\title{
MEDICAL SERVICES IN GERMAN SOUTH WEST AFRICA
}

Great Britain declared war on Germany on 4 August 1914. Six days later the South African Government agreed to take military action against German South West Africa. On 14 September the first troops embarked, and after a successful campaign the German forces were forced to surrender on 9 July 1915. Military hospitals were established at Swakopmund, Lüderitzbucht, Karibib, Windhoek and Aus. Casualties to the South African forces were: ${ }^{1}$
Killed in action …................................ $\quad 88$

Died of wounds ................................ 25

Died of disease and accident $\ldots . . . . . . .153$

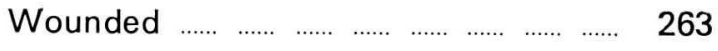

Several photographs illustrating aspects of the work of the medical services follow.

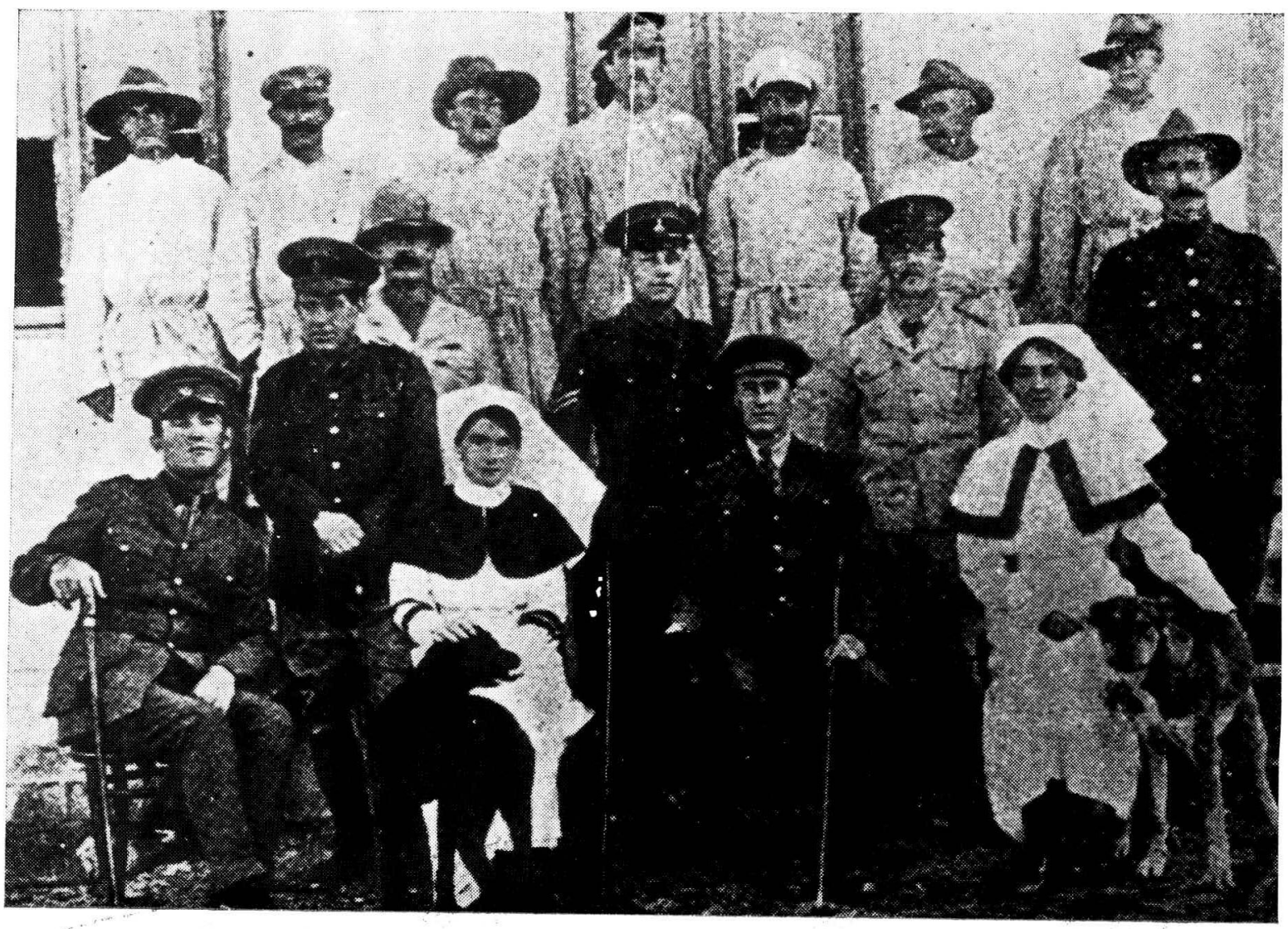

Patients and staff at Aus.

1. Collyer, J. J.: The Campaign in German South West Africa, 1914-1915, p. 152. 


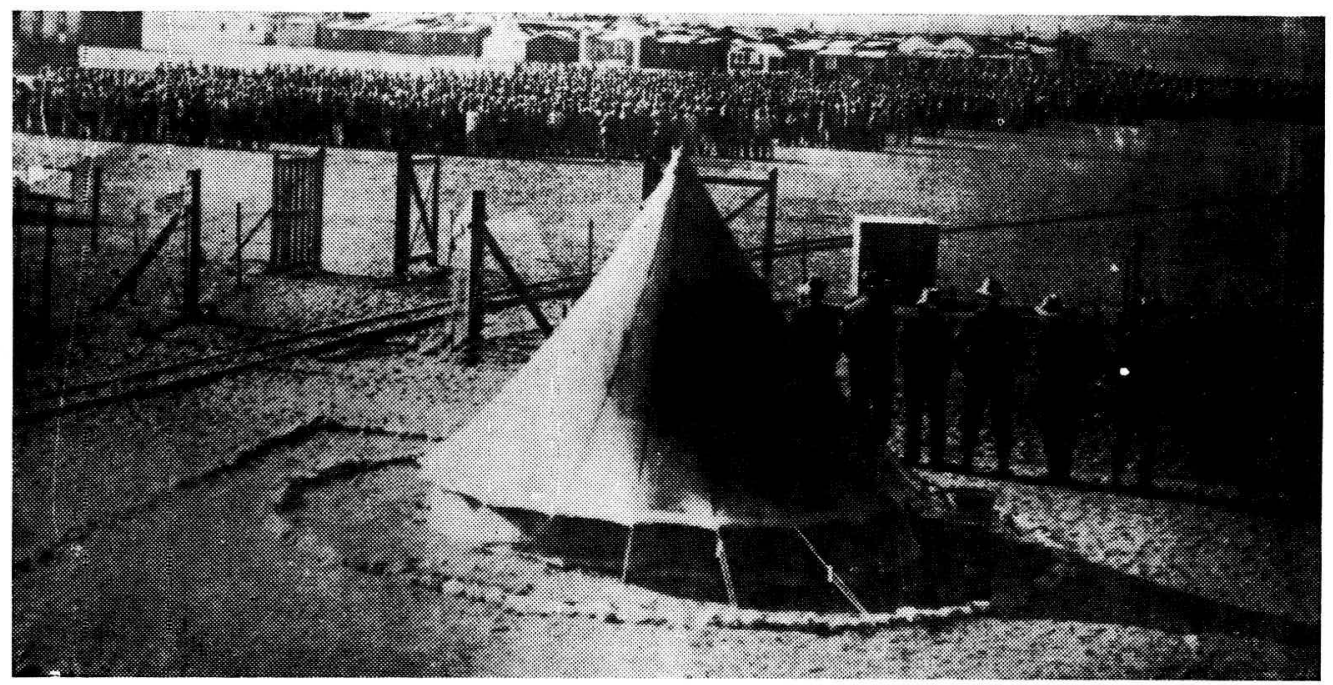

The hospital at Aus. The men massed in the background are German prisoners-of-war.

Photograph: C Doc S

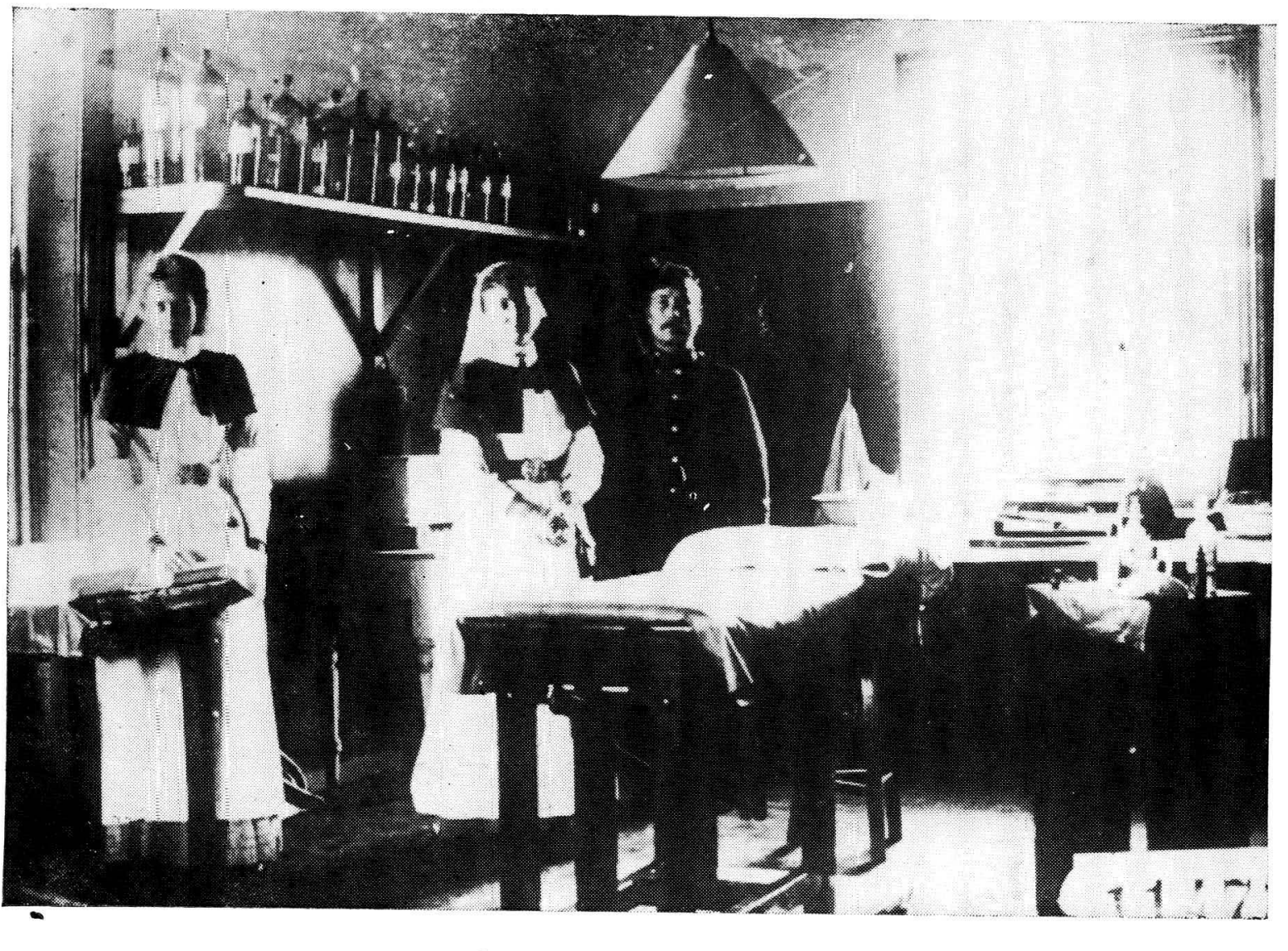

Inside a military hospital.

Photograph: C Doc S 


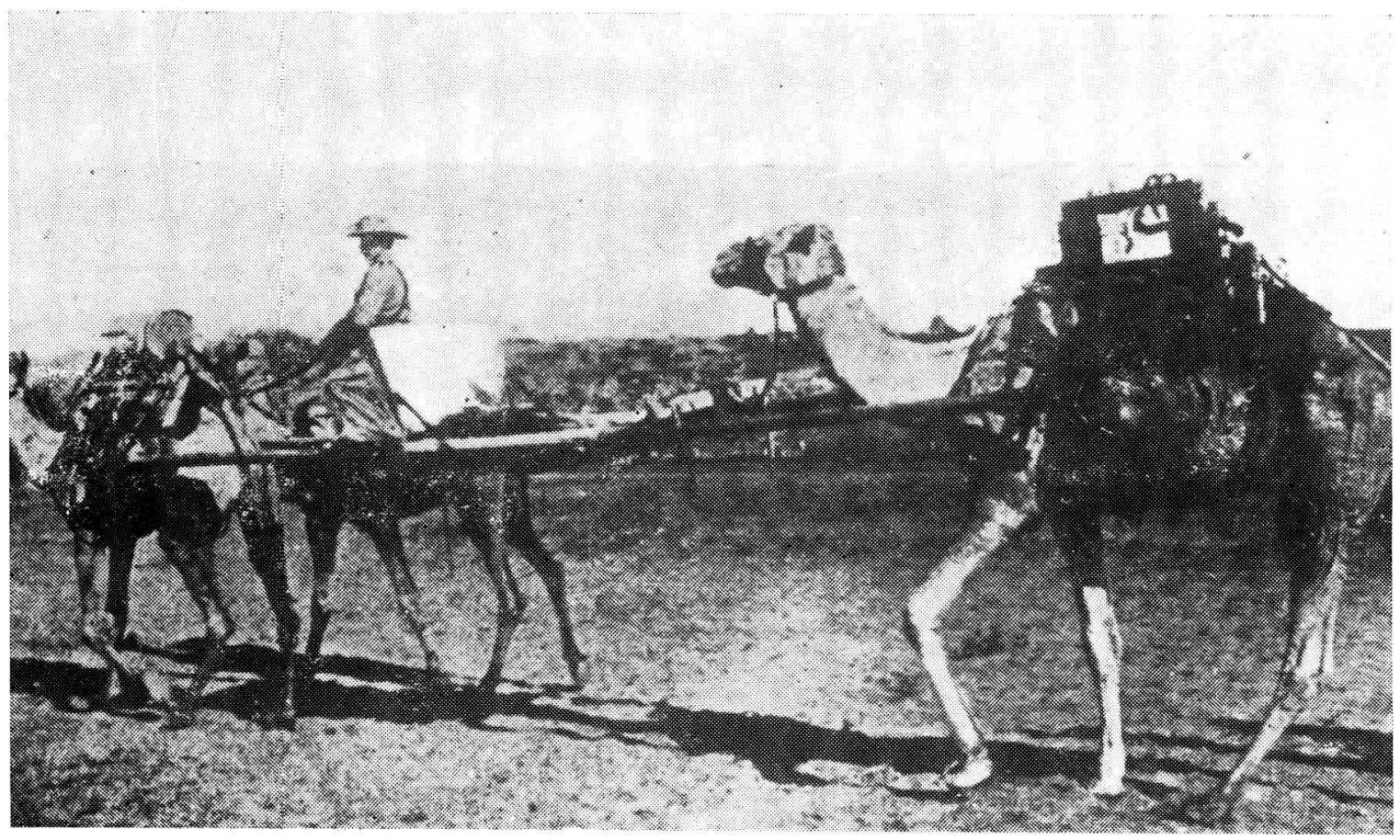

German camel ambulance.

Photograph: C Doc S

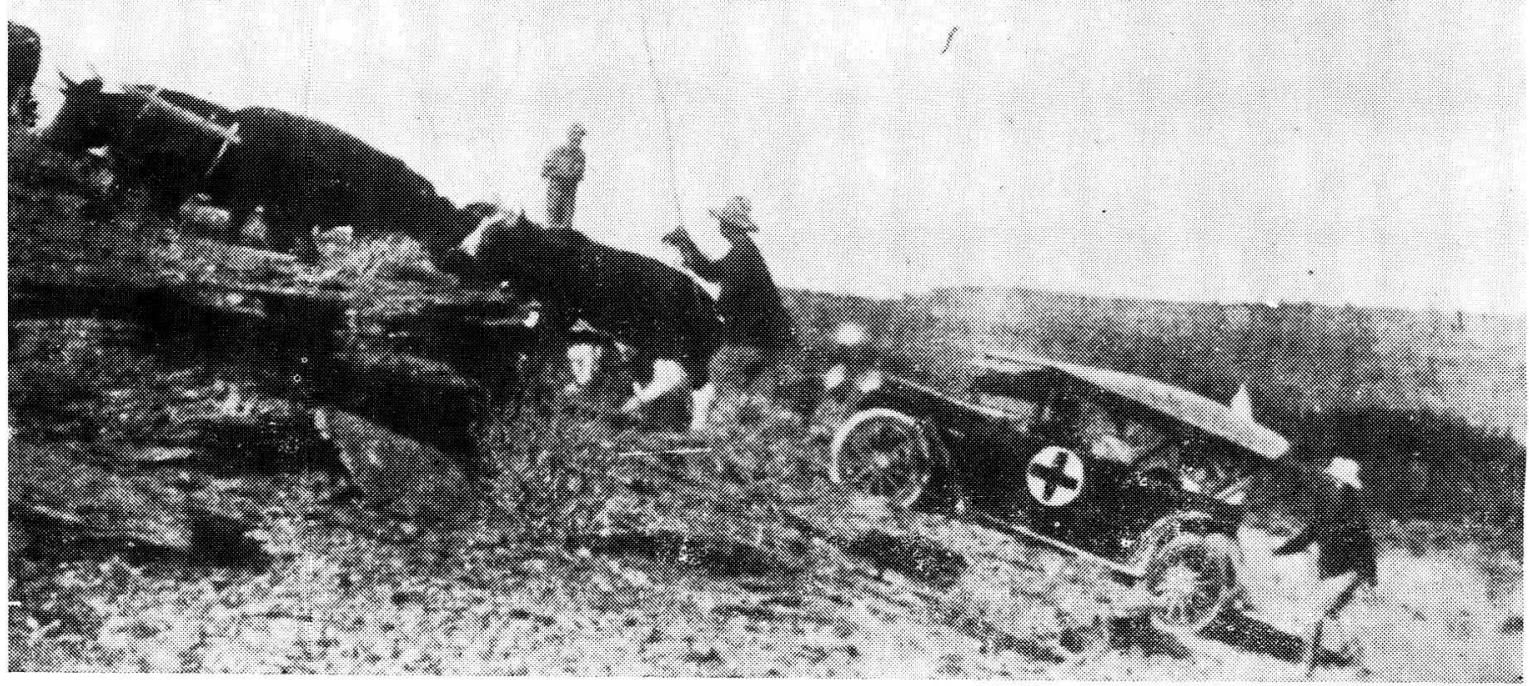

The laborious business of taking a light motor vehicle through the Great Fish River.

Photograph: C Doc S 


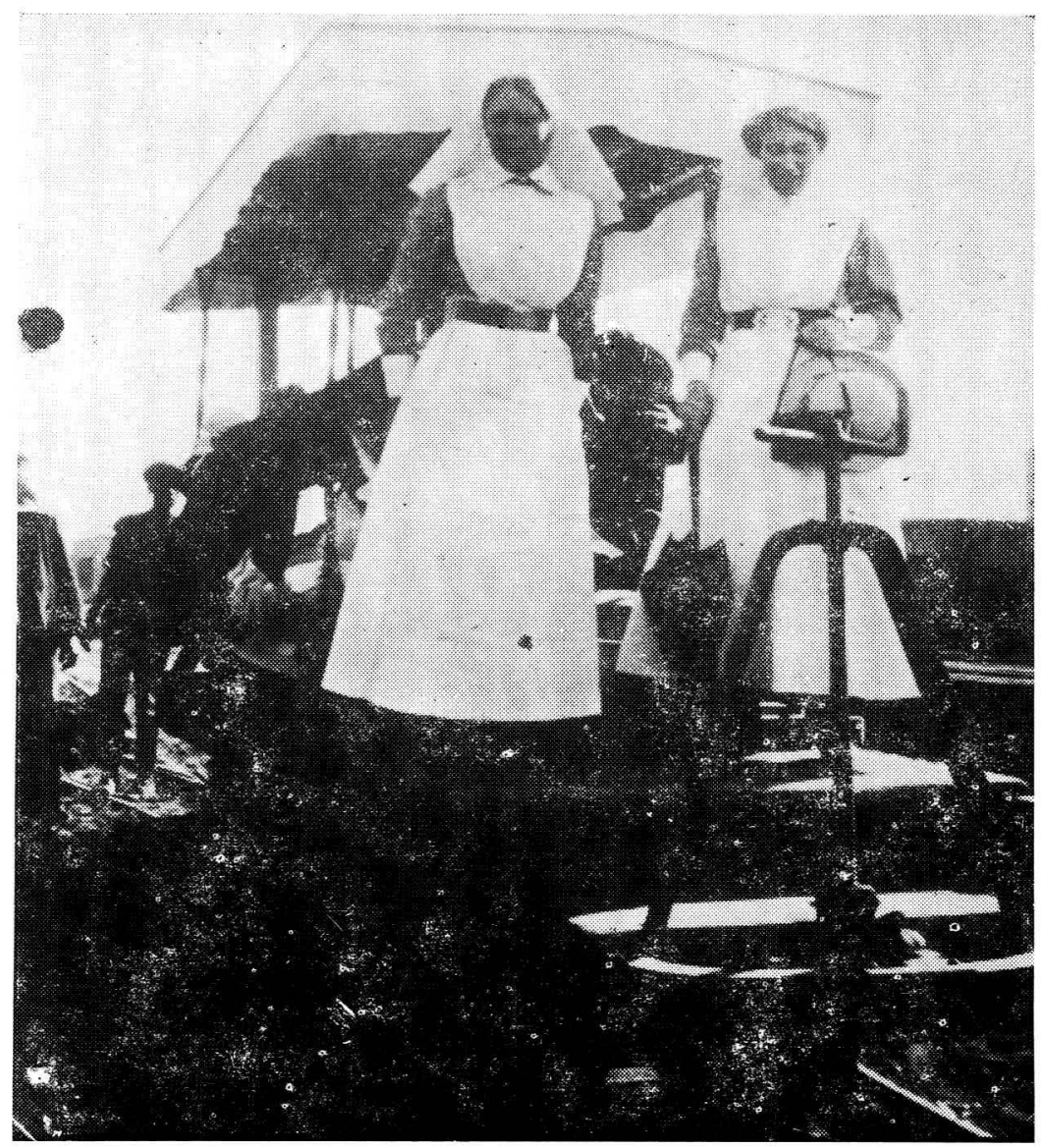

Sisters L. Campbell and M. Blinck arriving in Lüderitz from the hospital at Aus.

Photograph: C Doc S 


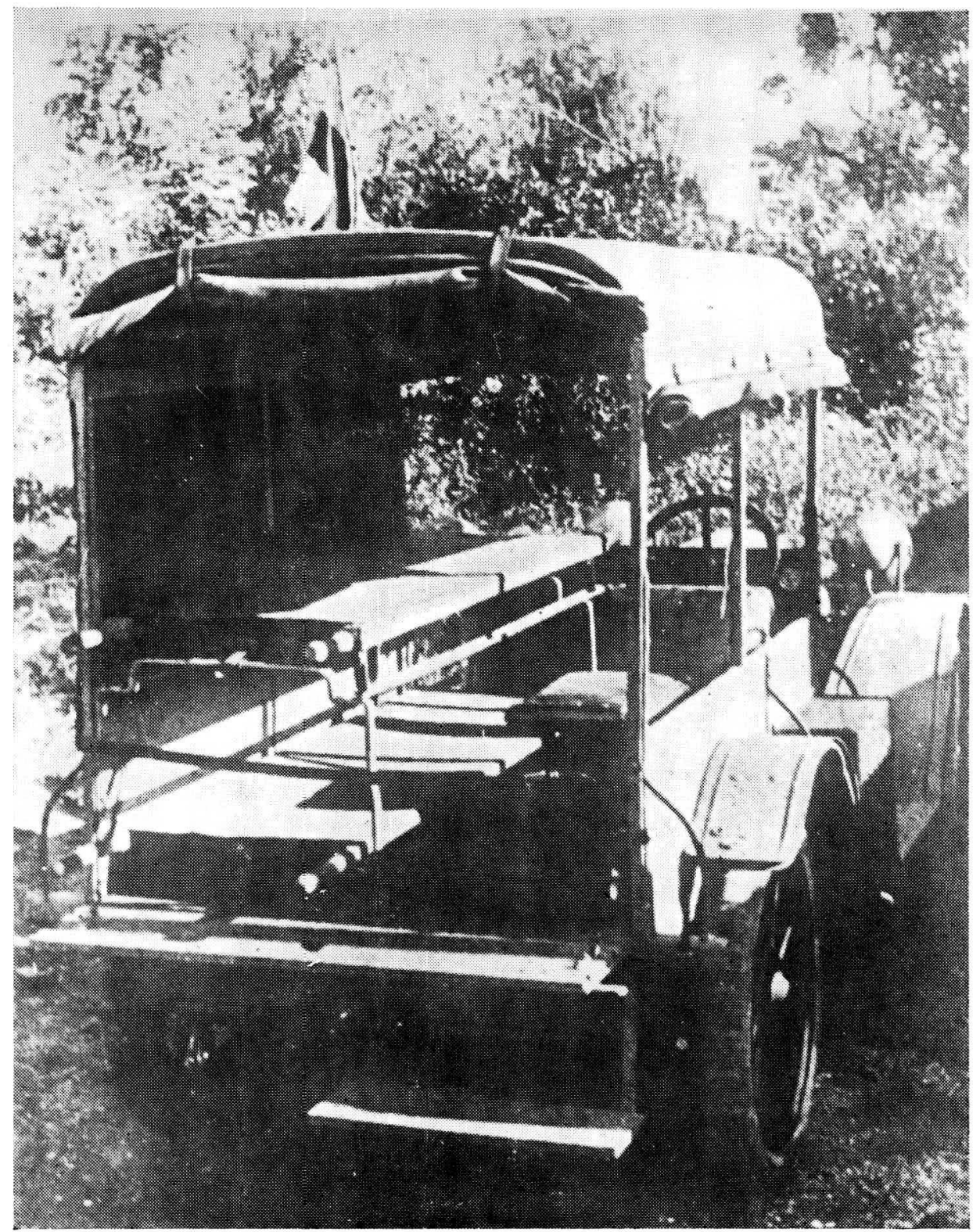

An ambulance of the type employed during the campaign.

Photograph: C Doc S 